\title{
Performing self: Questions of identity competence in a virtual world point to real life constructions ${ }^{1}$
}

\author{
Jennifer Meta Robinson, Indiana University, Bloomington, U.S.A.
}

Throughout our interactions in everyday life, we deploy and negotiate symbols, genres, allusions, implications, and consequences in a rapid-fire manner that informs our lives. In this process, we become desensitized to the familiar, often overlooking even graceful and artful enactments of everyday life. Life-like engagement in virtual worlds can point to divergences from routine expectations in ways that help us to see more clearly the stream of performances that constitute our everyday communication and culture. Although digital media use incorporates and adapts many of the same tools that we use face-to-face in verbal and nonverbal communication, distinctions can provide useful distance on often overlooked norms and assumptions. Using performance theory's attention to expressive language, emergent enactment, and competence, I argue that the constructed nature of social dynamics in virtual worlds illuminates the constructed and performative nature of those in everyday life. This perspective from a remove that digital encounters provide - mediated by screens, typed conversations, and graphical avatars - shows the nature of self to be both expressive and collaborative, not only in a digital reality but also in so-called "real life." An ethnographic examination of interpersonal communication in a virtual world uncovers how the technology of virtual worlds reveals the technologies of culture and how both are a means for shaping our experience of the world and for revealing the world we seek to know.

This essay follows Trevor Blank's 2009 call for a folkloristic approach to the internet that goes beyond finding simple correspondences between, as Barbara Kirschenblatt-Gimblett puts it, "the paperless office and the paperwork empire," looking instead toward "consequential differences" that help us understand communication and culture (Blank 2009, p. 6; Kirschenblatt-Gimblett 1995, pp. 72-73). Blank notes folklore's potential as a "'mirror' of societal and cultural views" (p. 4) even when it does not partake directly of Dan Ben-Amos' definition of folklore as "situations in which people confront each other face to face and relate to each other directly" (Ben-Amos 1971, pp. 12-13). Although none of the essays in Blank's book Folklore and the Internet (2009) take up simultaneous enactments such as occur in the life-like environments of virtual worlds, this kind of site offers

\footnotetext{
1 This paper was originally presented at the conference of the International Society for Ethnology and Folklore (SIEF), Lisbon, April 2011. A related paper has been published as Robinson 2012.
} 
particularly useful glimpses into the interplay between the individual and the social in emergent performance.

The site of my study in this essay is "virtual reality," a newly realized, digitally enabled invention that juggles dual ambitions to both simulate and supersede the "real" world in which we live every day. Continuing a trajectory that includes daydream, storytelling, theater, fiction, and simultaneous social invention, performances in virtual worlds offer both fidelity to the conventions of actual life and productive divergences from it. My focus is on "the action that happens" (BenAmos 1971, p. 10) and its potential, as an expressive point of culture, to "offer an especially productive vantage point on culture, society, and communication" (Bauman 1986, p. xiv). Although Robert Glenn Howard points us to folklore's defining characteristic as having "continuities and consistencies' that allow a specific community to perceive such expression as traditional, local, or community generated" (Howard 2008, p. 201), deviation from this consistency is the opposition that enables continuity. Although this study focuses primarily on language use among participants in a virtual world, the simulated " $3 \mathrm{D}$ " environment populated by human and other avatars recognizable as proxies for people at their keyboards is ripe for more explication of (dis)embodied performance.

I assume a phenomenological approach to the study of social dynamics on the internet, examining "that which shows itself from itself," as Martin Heidegger puts it (Heidegger 1962, p. 51). To understand interpersonal interactions, then, we must look to what we can perceive of them and what they tell us about their own nature, while being sensitive to context and circumspect about mere appearances. We do, as Heidegger indicates, "always find ourselves surrounded by particular objects and items of equipment, and caught up in particular activities and goals, all of which contribute to making up a particular situation" (Wrathall 2005, p. 11). Thus we cannot simply read chat logs or look at other manifestations of culture without knowledge of that context, without fieldwork, even when the field seems intangibly virtual. We must seek the meaning-in-context generated by the convergence of conventional, patterned organization and unique, emergent enactment as used for immediate purposes during the interaction of particular people (Bauman 1983, p. 362).

Our usual negotiations of all of these complexities seem instantaneous and largely seamless. Media that we use for sufficient time or ubiquitously become "depresenced" for us, slipping below the threshold of awareness and into invisibility, even as our experience through them does not escape mediation (Hansen 2010). Thus, for all of our capability to reflect on our own behavior, we often operate relatively obliviously, not consciously reflecting on how we are bringing ourselves into being as "a complex product of the decisions [we] make, the skills and habits and practices [we] foster, and the objects, institutions and other worldly structures within which [we] find [ourselves]" (Wrathall 2005, p. 16). Interaction in a simulated, virtual world introduces a degree of defamiliarization that can allow for reflection on social and individual performance. 
The ethnographic method, clearly, is powerful for documenting what is there and how people live as well as how phenomena are perceived and what meaning is made from them by particular people. Heidegger asserts that "Technology is [...] no mere means. Technology is a way of revealing" (Heidegger 1977 p. 318). By this, he suggests that technology is not only a tool for making but also sets the world in which it operates in an order. "It unlocks and exposes" the nature of things so that they can be used apart from any natural function, or natural conditions under which they occur even while that unlocking exposes the natural "manifold interlocking path" that are now set about to different ends (p. 322). Culture, too, is a technology. With culture, too, we are able to transform "objects" into resources that can be redeployed from typical uses and in that redeployment expose their earlier uses. And although Heidegger indicates that this "unlocking, transforming, storing, distributing and switching about" (p. 322) renders objects into insignificance, he offers us a way out of emptiness through context, suggesting that attention to context (as constructed through intersections of locality and universality, mortality and divinity) allows us to reassemble a sense of coherence in which meaning can be realized.

Thus, deconstructing the seamlessness of everyday life with the reflective tools of virtuality, in conjunction with the context- and meaning-building activities of ethnography, can help us to see the technology of culture. Through the technological interface, culture reveals itself as an emergent negotiation of tradition and innovation, individual and community, real life and "second" life.

\section{Setting the stage for the conversations}

I focus in this article on one digital site in which I have conducted ethnographic research, the virtual world called Second Life. As Patrick Lichty (2011) rightly notes, Second Life is not a game but a toy, one that allows for "free play" in a "sandbox" environment rather than structuring participants' engagement through rules, quests, points, or other scripted behaviors and motivations. As a result, he says, while other media might offer more visual realism, none equals the social veracity of Second Life.

The interactions that follow involve small groups of people hanging out in a philosophy "sim," a digitally simulated space that is designed to look like a threedimensional world. In this case, people who are physically sitting at their keyboards in many different countries appear on screen as though they are gathered, seated and standing, around a campfire, discussion table, or other configuration. They are able to type, speak, and move synchronously and independently. Most likely, no one present has met any of the others face-to-face in the physical world, although occasionally that happens. The names of avatars are invented by the person initiating the account with Linden Lab. One can assume that both men and women are present, although one can also assume that the gender, race, or other 
disposition projected by an avatar does not necessarily represent the real life actuality of its account holder. For example, male avatars are not necessarily animated by real life men, and dragon, wolf, or robot avatars almost certainly reflect an altered appearance! In this particular sim, text-based chat is the most typical instrument of communication, though speaking by voice to others nearby is also possible. All those present can be assumed to be over the age of 18, the minimum age required by the Second Life program's terms of service. As each person types a comment, his or her messages appear on screen to all within a few "meters" of the speaker. Each message is preceded by the name each person has given his or her avatar, so as lines are added, the conversation looks like the dialogue in a play or the transcription of a conversation. The difference, of course, is that this chat interaction is not scripted by a single person, is not predictable, nor has it been transcribed from one medium to another: this $i s$ the conversation.

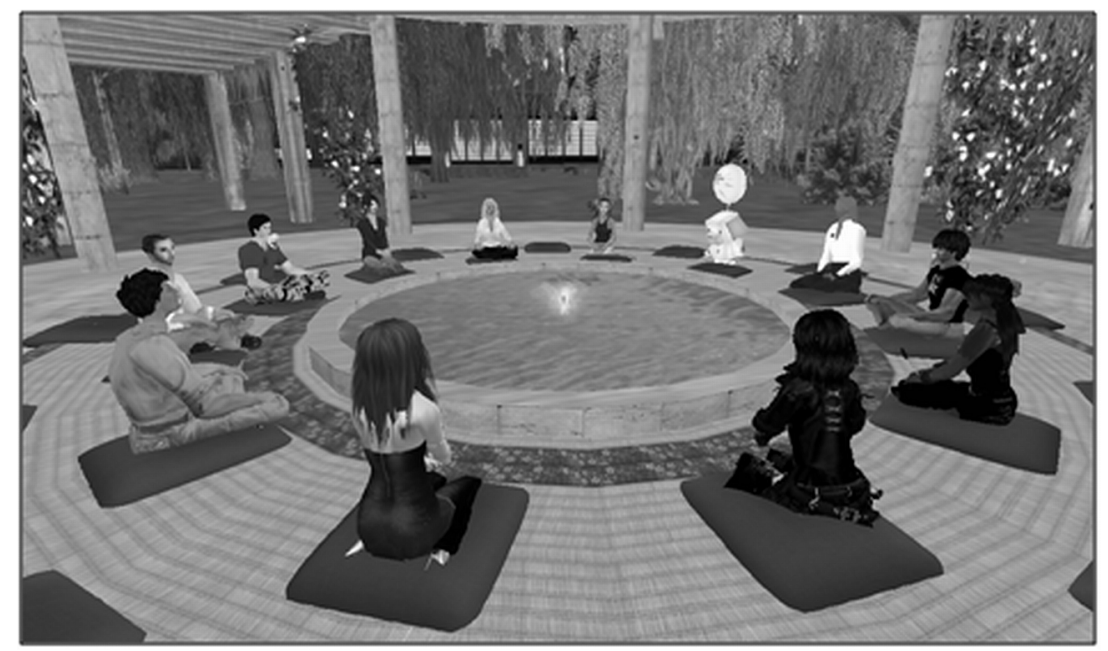

Discussion in a Second Life philosophy sim

As with any social group, it is important for the newcomer to develop familiarity with local conventions. Virtual worlds can pose particular challenges. For one thing, an investigator new to that medium may believe that she is equally as fluent in social interactions in the new space, not least because everyone present has to be relatively new to a new medium. Moreover, the ostensible similarities to off-line life (human-like figures chatting in spaces that simulate the three-dimensional world about familiar topics) may make translation appear more seamless than it actually is. Overconfidence on the part of the ethnographer that results in rushed and superficial familiarity with the culture can lead to misinterpretation, as could happen with any foreign culture. Instead, the thorough visitor must give sufficient time to observe and participate, letting the medium, social structures, and characters show themselves with some clarity and reveal their own internal logic. 
Ethnographers in the "real" world have learned to wait out their initial responses to penis shields, drag costumes, unpalatable foods, and other unfamiliar means of communication, and they should recognize a similar requirement for cultures wherever they find them - even those largely shaped by electronic spaces. Cultures, I would argue, should be understood first on their own terms and then scrutinized.

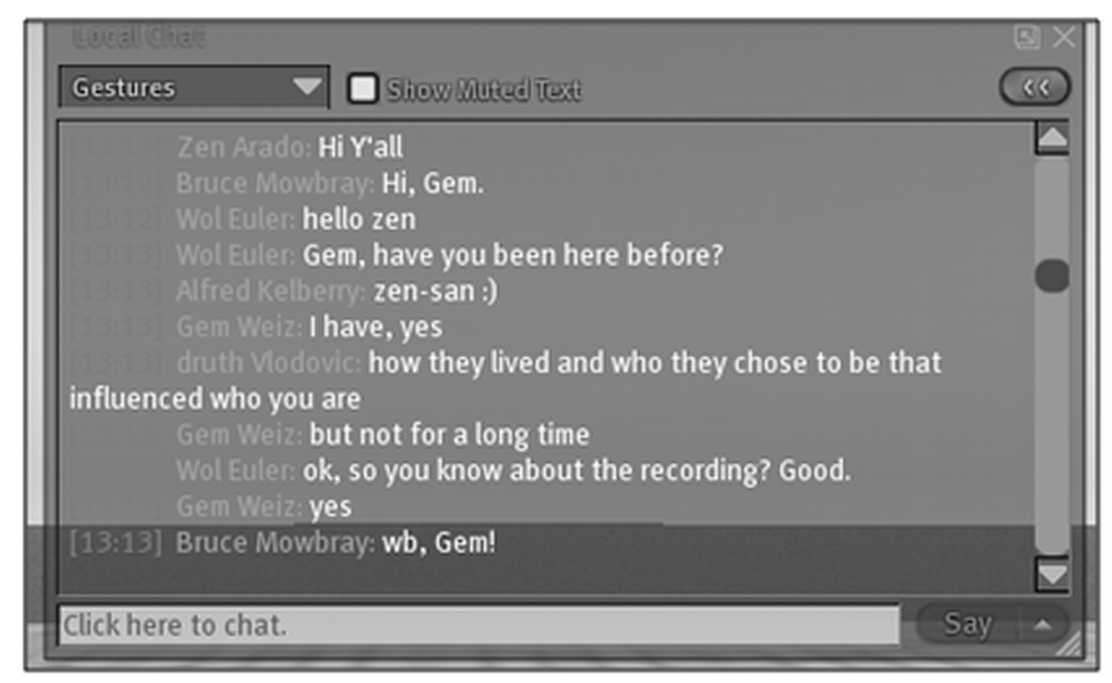

Text-based chat in Second Life

Because social life is real and consequential - that is, even pseudonymous and virtual social actions have consequences for relationships, status, power, and possibilities within a social group - I include here only exchanges available on public chat that is accessible for reading and recording by anyone nearby in the simulation. (Private instant messages between two avatars cannot be followed by others.) I further protect participants' privacy by changing their Second Life names here. In addition, while the conversations, other than names, are precise, my descriptions of the scenes they take place in synthesize multiple simulations that have overlapping membership so that I can further protect privacy. Collected during two years of participant-observation, I begin with greetings because this focused moment of entry into a social context is prime for establishing conventional and divergent language and their intersections with identity and the collaborative process of social competence.

A note about terminology. In this discussion, it is necessary and conventional to distinguish between the world that occurs on and through the screen as opposed to the world that happens more or less everywhere else (including face-to-face, by telephone, in writing, or by broadcast). Tom Boellstorff in his influential book Coming of Age in Second Life (Boellstorff 2008) uses the terms virtual and actual, respectively. Here I use the terms virtual and real because they are widely used in 
Second Life to reference these spheres of activity (Sometimes in practice the opposition is posed as $S L$ and $R L$ ). However, although identities and behaviors in the simulated world of Second Life both repeat and differentiate themselves from those in real life, virtual reality is not, then, inevitably in negative opposition to the real. Rather, the virtual is always and inevitably part of the real. ${ }^{2}$

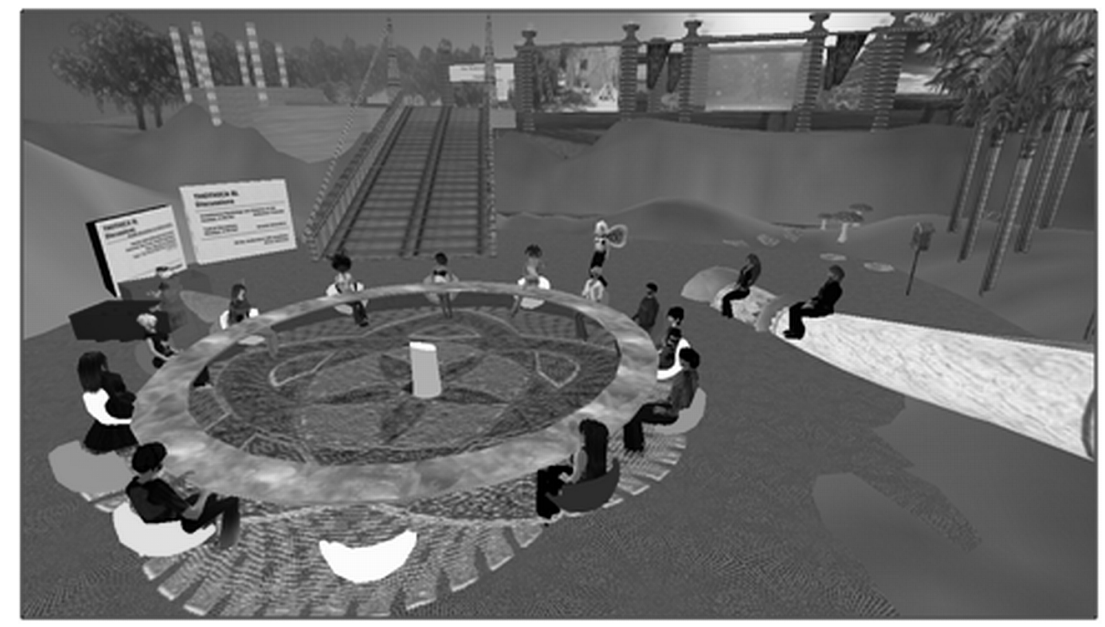

A philosophy discussion

\section{Saying hello}

The processes and practices of culture become more apparent through the lens of technology. Consider these typical greetings given when two avatars, Zen and Gem, enter a discussion-based philosophy sim:

[13:12] Zen Arado.: Hi Y'all

[13:12] Bruce Mowbray: Hi Gem.

[13:12] Wol Euler: hello zen

[13:13] Wol Euler: Gem, have you been here before?

[13:13] Alfred Kelberry: zen-san :)

[13:13] Gem Weiz: I have, yes

$[\ldots]$

[13:13] Gem Weiz: but not for a long time

[13:13] Wol Euler: ok, so you know about the recording? Good.

\footnotetext{
${ }^{2}$ Gilles Deleuze's philosophical meditation on Difference and Repetition (1968) is helpful here. He notes that the "primacy of identity" maintained among the simulacra of modern life does not mean that difference from that identity must be understood as negation: "We propose to think difference in itself independently of the forms of representation which reduce it to the Same and the relation of different to different independently of those forms which make them pass through the negative" (p. xix).
} 
[13:13] Gem Weiz: yes

[13:13] Bruce Mowbray: wb, Gem!

Reminiscent of a transcription of a verbal conversation, this text-based language encodes elements of spoken language by indicating prior acquaintance with a familiar name ("zen-san"), tone with word choice and punctuation ("Y'all" and "Gem!"), and acceptance into the group with a colloquialism ("wb" = welcome back). The tone indicated by facial expression is also indicated with the emoticon for a smile, being :) . You may recognize a fairly familiar exchange here, something along the lines of what might be said at the start of a face-to-face social gathering. Perhaps the only unexpected comment is the acknowledgement that the exchanges at this site at this time are being recorded for posting on the web.

In comparison to these normative examples of greetings, consider the entry of an avatar I'll call Gaia Watchman into another casual conversation in this virtual world. Gaia begins speaking without any of the standard greetings above. Instead, she uses a string of apparent nonsense phrases that point out the conventions of greeting by her deviation from them and reveal our experience of the world as one structured by the interplay of patterns and novelty:

[12:15] Gaia Watchman: lalala lalala la la la lala... I dont know if $i$ can yell any louder.. how many times have i kicked u outta here

$[\ldots]$

[12:15] Gaia Watchman: or said something insulting

[12:16] Gaia Watchman: i can be so mean when i wanna be.. i am capable of really everything.. i can cut $u$ into pieces....

[12:16] Minister Alleluja: lol!

[12:16] Juliette Dane: holy fuck, who woke the crazy up?

[12:16] Gaia Watchman: when my heart is.. broken.... la la la la la.. pleassseee dont leave me

[12:16] Gaia Watchman::)) juliette

[12:16] Gaia Watchman: haha

[12:16] Gaia Watchman: who dares SUMMON the LORD of LORDS??

[12:16] Gaia Watchman: the Watchman of Gaia

[12:16] Gaia Watchman: the faultless and perfect Light

[12:16] March Hare: nurse rachett does, she has your thorazine

[12:17] Gaia Watchman: haha

[12:17] Gaia Watchman: whats going on

[12:17] Gaia Watchman: what's everyone up to

[12:17] Minister Alleluja: well I know a lot of people who've been prayin for a lot of stuff for a long time, you should really check your inbox

[12:17] Gaia Watchman: i'm listening to PINK "Dont leave me"

[12:17] Minister Alleluja: could be quite a backlog up in there of miracles needed 


\section{Notes}

- A conversation is in progress when Gaia Watchman begins speaking without a conventional greeting.

- An ellipsis in brackets indicates I have deleted text for readability. Any periods outside of brackets are original.

- Timestamps are automatically generated and appear in brackets.

- I have changed the avatars' names, but I have attempted to preserve any relevant allusions in the pseudonyms I have assigned.

- The participants encode numerous extra-linguistic features in their chat. For example :)) iconically represents a big smile, and capital letters convey volume and emphasis. Other expressive orthographic features include successive punctuation symbols $(. ., \ldots, \ldots . . . .$. , and ??), onomatopoetic exclamations and variant spellings ("ha ha" and "pleassseee").

- Nurse Ratched (not "rachett") is an antagonistic character in Ken Kesey's novel One Flew Over the Cuckoo's Nest (Signet 1960), in which Randle McMurphy ducks a prison sentence of hard labor by acting antisocial enough to warrant incarceration in a mental institution. Thorazine (chlorpromazine) is an antipsychotic drug used to treat symptoms of schizophrenia and disorders involving aggression and anxiety that interfere with balanced and socially accepted behavior.

- "Please Don't Leave Me" (2009) is a song by the American pop music star Pink or P!nk (Alecia Beth Moore).

The very ordinariness of the act of entering a room makes it a promising backdrop to examine the dual nature of social performance, incorporating conventional, patterned behavior and individual emergent enactments, what Richard Bauman calls "the emergent quality of performance" (Bauman 1977, p. 37). In this case, the avatar called Gaia Watchman eschews the norms of expected greetings, launching a performance that foregrounds the contextual, inter-textual, and collaborative nature of everyday life.

Gaia begins without an obvious frame that would help her audience interpret her performance through the usual vocal, visual, and physical signals. In our example, Gaia begins not with "hi" or "hello" but with her nonsense sequence of "lalala lalala la la la lala." She then continues with language that appears to be confrontational: "I dont know if i can yell any louder.. how many times have $\mathrm{i}$ kicked u outta here." She continues: "or said something insulting / i can be so mean when i wanna be.. i am capable of really everything.. i can cut $u$ into pieces..... ." She does not frame these comments so that they appear to be typical greetings or in some other way that allows her audience to make immediate sense of them. Without a frame of reference, the audience reacts with "lol!" and "who woke the crazy up."

However, Gaia is not "crazy." Her own performance responds playfully and collaboratively to her audience. When Juliette responds with "holy fuck," Gaia deliberately misunderstands the pragmatics of that phrase, taking it to be an address rather than an exclamation. Accordingly, Gaia changes her communicative register 
to respond to "holy" with voice-of-god theatrics: "who dares SUMMON the LORD of LORDS??" In contrast to her earlier use of the lowercase " $i$ " for the singing persona several lines earlier, in this new movement in her performance, Gaia uses all capital letters to suggest power and a booming volume, playing on the divine origin of the name of her avatar. The next two lines continue the supernatural allusion, speaking of herself in the third person as though reading from a religious text and attributing super-human perfection to "the Watchman of Gaia / the faultless and perfect Light."

Acting more as creative collaborators than audience, Gaia's listeners pick up the cues she provides and tailor their own contributions to the interaction accordingly. March Hare uses the same pattern of humor that Gaia has established by alluding to an external text. March refers to characters in a popular novel that was also made into a movie. He alludes to Ken Kesey's One Flew Over the Cuckoo's Nest, in which the main character ducks a prison sentence of hard labor by acting antisocial enough to warrant incarceration in a mental institution. The novel's character is not clinically "crazy," to use the term just assigned to Gaia, but rather acts sufficiently outside social norms to be prescribed the drug Thorazine, electroshock treatment, and finally surgical lobotomy as members of a rigid institution seek to control his divergent behavior. Knowledge of that text lends logic to his comments about nurses and drugs - but again, only if one knows the reference. To Gaia's imperious question, "who dares SUMMON the LORD of LORDS??" March rejoins with a set-up and punch line couplet: "nurse rachett does, she has your thorazine." Presumably said with humor, March's comment nevertheless conveys his assessment that Gaia has diverged from conversational norms.

At this point, Gaia Watchman makes another shift in her performance. She signals the shift with a disclaimer, the single line "ha ha," through which she concedes to the standards of communication that are conventional in this situation. Such disclaimers are both a moral gesture, a sort of apology for breaking the rules, and a key that the performance is closing and the speaker is moving out of that frame. Gaia actually uses this signal twice, first to shift out of the " $\mathrm{l}$ " of the opening performance that began with "lalala" and second to close the "LORD of LORDS" performance. After this second closing of the frame of the performance, Gaia shifts into a more conventional voice, greeting those present as she failed to do earlier and inviting them to take the lead on defining the rest of the discussion: "what's going on / whats everyone up to." And a moment later she provides the missing key to her initial performance, saying, "I'm listening to PINK 'Don't leave me." The reappearance of the lowercase "i" provides continuity with her earlier performance, suggesting that Gaia at the keyboard is really not so pretentious (or crazy) as to think she is god and that she "really is" listening to music while also visiting the sim. With these signals, Gaia clearly indicates her performance is bounded, short-lived, and artful, rather than leaving her audience with indications 
of a truly incoherent individual who might actually need medical intervention like hospitalization or Thorazine.

An important feature impacting the collaborative nature of performance in this world is "lag." "Lag" in the context of digital communication refers to a lapse in time between when information is sent and received, the duration of which can be influenced by many factors (the person at the keyboard being distracted, an individual's computer hesitates in its processes, a server on which the program is stored running slowly, traffic on the communications systems being slowed, and so on). For lag in chat, specifically, time can lapse between when a message is sent, transferred, received, responded to, retransferred, and received again. In the interim, other comments can be made, so that the progression of a conversation can seem undirected by usual, face-to-face standards. Gaia's mention of the singer Pink instantly provides the reference necessary for the other participants to understand her - she was singing along to a song in a kind of text-based karaoke. The first few lines of Please Don't Leave Me by Pink can be transcribed:

Da da da da, da da da da

Da da da, da da

Da da da, da da

I don't know if I can yell any louder

How many times I've kicked you outta here?

Or said something insulting?

Da da da, da da

I can be so mean when I wanna be

I am capable of really anything

I can cut you into pieces

When my heart is broken. ${ }^{3}$

But while she closes out her performance, other participants continue to respond to it. During the lag in Gaia's comments, Minister Alleluja takes up Gaia's allusions to a deity and plays with that meaning, following March's format by offering her own couplets of set-up and punch line: "well I know a lot of people who've been prayin for a lot of stuff for a long time, you really should check your inbox." And then, a little later "could be quite a backlog up there of miracles needed." With such interactive play with context and form, the exchange unfolds as a collaborative project of multiple participants responsive to and actively shaping their collective context. In this way, lag becomes part of the context in which this virtual performance is emergent, responsive to and constructing the situation in which it occurs.

Technology also is a factor in the specialized way in which Gaia controls the frame of the exchange. The others present don't have access to her immediate

\footnotetext{
${ }^{3}$ Moore 2010.
} 
physical environment and cannot hear the song she is singing along to, which is presumably quite audible in a room in some unspecified place in the physical world. They may even be unfamiliar with the specific lyrics of the Pink song. However, their reactions indicate they do not have access to the information that would bring her behavior into logical order. The virtual reality technology allows her to be present in the sim and simultaneously somewhere else. Likewise, the technology of culture allows her to engage the norms of behavior while also deviating from them. Gaia plays with both the technology of the medium and the technology of culture.

Similarly, Gaia's creative portrayal of a divine figure is signaled not only by content (her name and what she says) but also by form (her biblical-type syntax and bombastic volume rendered in text). She uses special formulas of language appropriate to popular notions of divine entities, representing those in text in rhythmic, incantatory naming of herself: "the LORD of LORDS," "the Watchman of Gaia," and "the faultless and perfect Light." The repetition of the grammatical structure, the iambic meter, and the cumulative effect of metaphors for god create a sense of invocation. An ostensible embodiment of a god, Gaia is seen and unseen, heard and unheard. She stands with one foot in cultural allusion and the other in the technology of her performance.

Minister, meanwhile, plays with the notion that a God who makes electronic appearances might also have an email inbox: "you really should check your inbox." In Minister's estimation, "god" is not holding up her end of the human-god relationship, not performing duties that might be expected of a deity, noting that there are "miracles needed" that are not being provided.

Thus, the performance unfolds interactively, blurring distinctions between performer and audience as they creatively apply rules of engagement that are "neither sheerly random nor rigidly determined" (Eagleton 2000, p. 4). The speed with which all participants formulate jokes and word play, all in two minutes from start to finish, is a sign of their proficiency in this communicative context. Using each other's comments to springboard his or her own contributions, the participants create a collaborative performance that constructs and reconstructs identities between poles of convention and invention, in ways that are mutually constitutive. If novelty exists, it relies on their knowledge of what is conventional, and conventionality is spotlighted with the novel. Similarly, virtual life does not exist without the contrast of real life.

\section{Identity and anxiety}

Gaia's off-beat greeting with its tensions regarding the collaborative nature of identity performance heightens the sense of a gap in a formerly seamless world, introducing a certain anxiety. The digital remove creates physical, temporal, and cultural gaps that have implications for individuality/society, reality/virtuality, and 
identity/difference. Gaia's virtual lip-synching of the pop song and her playful animation of biblical language by god's "Watchman" bear some similarity to the degrees of scripted interaction that are commonly encountered in Second Life.

For example, objects in Second Life can be programmed to insert lines into the chat interface. A scripted horn, much used in 2010 in South-Africa during the World Championship soccer tournament, produces the following line into nearby conversation: "Vuvuzela! Touch to make noise!: Toot toot!" Comments by these sorts of objects may be timed or may be triggered by being touched by an avatar, as with this Vuvuzela horn.

More sophisticated, "bots" are avatars conventionally controlled by humans that are actually controlled by a computer program that generates human-like conversation. For example, a bot appeared at the sim on a different day to begin this exchange:

[11:58] Hal Cybertar: type "Hello Hal" to give my program permission to speak with you.

[11:58] Jer Dix: Hello Hal

[11:58] Hal Cybertar: I have wanted to see you, Jer!

[11:58] Jer Dix: show us how good you are

[11:58] Hal Cybertar: Same to you Jer!

[11:58] Hal Cybertar: A good talk show guest can chatter amusingly for seven minutes.

[11:58] Jer Dix: flaws already

[11:59] Hal Cybertar: Jessie Flaws (born August 13, 1935) is an actor born in Bridgeport, Connecticut u.s.

The programmed bot has human avatar form and is relatively sophisticated in its comments able to seize on individual words said by its conversation partner ("show" and "flaws") but cannot sustain a conversation that is convincingly animated by meaning. In philosophy simulations, people who are repetitive in their comments or less than creative in their thinking (such as with extensive quoting) are sometimes critiqued as "bots," such as in this exchange:

[14:40] Allysia Caryssa: o! hi sweet trane and sweet terry ! i didnt see $u$ there $[\ldots]$

[14:41] Trane Kelly: lo

[14:41] Trane Kelly: "I had reached a spiritual stage in which Sanna -- pure perception -- had ousted Vedana -- sensation -- I had learnt to look on the world without being affected by events. I was able to observe what went on as few people can, for the average man's senses are deceived by his emotions. He gets things out of proportion and he exaggerates them even when he is able to appreciate them at all.

$[\ldots]$

[14:42] Allysia Caryssa: $\mathrm{r}$ u a robot in $\mathrm{rl}$, trane?

[14:42] Trane Kelly: one day I hope to be a robot 
$[\ldots]$

[14:43] Allysia Caryssa: u speak as tho $\mathrm{u}$ have already reached that stage, sweet trane

Allysia's critique of Trane's comments is not unusual, as many participants in this simulation consider Trane's comments to be longer than typical and tangential. Although she has proved herself over time not to be a programmed object but a human at a keyboard who is represented in Second Life by an avatar, in many of her comments, Trane is not much more responsive to the dialogue than Hal the programmed bot. Moreover, in a venue with participants who value originality and/or socially marginal identities engaging in the technologies of cultural convention, alone, may seem to render ordinary humans bot-like:

[17:53] Juliette Dane: can people be bots? sure.. no thought.. get up go to work, go home, do what your parents did, dont think, dont question... flesh and blood bot arent $\mathrm{u}$

[17:53] Demetrius Serba: all bots shall be watching football tomorrow i suppose

Technologically enabled short cuts to cultural convention also serve to muddy the issue of collaborative construction of identity and reinforcing the convergence of technology and culture. At Second Life dance clubs, staff members typically have as part of their role greeting patrons, urging monetary donations, and generally exuding cheery enthusiasm. To do this rather repetitive job, they often use stock variations of standard greetings that can be copied and pasted or otherwise mechanistically inserted into the chat stream for those in the vicinity to read. For example:

[12:15] aci Heart: DON'T FORGET TO TIP YOUR ROCKIN' DJ , AND HOST, WHO ARE HERE FOR YOU!

[12:15] aci Heart: WOOOOOOOOHOOOOOO PPARTY NAKED!!

$[\ldots]$

[12:15] anastefania Narget: *****

APPPPPPPLLLLAAAUUUSSSSEEEEEEE***********

$[\ldots]$

[12:15] anastefania Narget: $* * * * *$

APPPPPPPLLLLAAAUUUSSSSEEEEEEE*********** $[\ldots]$

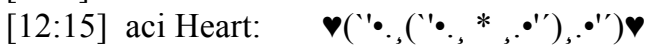

[12:15] aci Heart: $\vee \vee$ SHOW SOME LOVE $\vee \vee$

[12:15] aci Heart:

[12:15] aci Heart:

[12:15] aci Heart:

$\bullet \vee \vee T O$ OUR $\vee \vee \vee$

$[\ldots]$

[12:16] aci Heart: DON'T FORGET TO TIP YOUR ROCKIN' DJ , AND HOST, WHO ARE HERE FOR YOU! 
These comments are clearly automated in some way, with not only the precise number of asterisks and letter repetitions in the extended vocalized gesture of "APPPPPPPLLLLAAAUUUSSSSEEEEEEE" but also a stray space between "DJ" and its following comma being repeated. Moreover, the decorative exclamation to "SHOW SOME LOVE TO OUR DJ" was likely programmed in advance as a "gesture" that could be launched with as little as one keystroke (sometimes referred to as "gesture spam"). While these comments may be automated to some degree, used effusively to convey enthusiasm by taking up space through repetition and elaboration, they are the work of inhabited avatars, not bots or other scripted objects. Even while applauding and otherwise welcoming patrons with conventional comments, they may be interleaving spontaneous comments and carrying on private conversation via instant messaging that is appropriately collaborative for one-on-one communication. Nonetheless, the conjunction of the technology of this virtual world and the technology of culture serve to underscore their similarity.

Such similarity, too, reiterated in these various ways and through these various sites of performance, suggests a troubling of identity. During my fieldwork, one of the most vocal participants in the philosophy simulations was Juliette Dane who purposefully plays with gender identity. Although her avatar is a very feminine female, she complicates that presentation by using a photograph in the " $1{ }^{\text {st }}$ Life" section of her profile at that time that shows an obese man naked from the waist up and sitting at a computer. On one occasion, the dissonance caused by these two representations indicated the collaborative nature of identity competence. As with any performance, Juliette's gender is subject to evaluation by her audience:

[12:38] Hugo Sabastien: juliet ur a guy, right?

$[\ldots]$

[12:38] Juliette Dane: ahaha yeah I am

[12:38] Parenthesis Equation: yeah she's a big fat dude. havent you seen her profile pic?

[12:38] Juliette Dane: HEY!

[12:38] Hugo Sabastien: no

[12:38] Juliette Dane: I'm not fat, i'm just big boned:(

[12:39] Hugo Sabastien: i just believe my eyes

[12:39] Hugo Sabastien: lol

[12:39] Parenthesis Equation: Sorry, sir. No offense meant

[12:39] Juliette Dane: your eyes lol

[12:39] Vuvuzela! Touch to make noise!: Toot toot!

[12:39] Juliette Dane: yes, Juliette really looks like a dude ${ }^{4}$

[12:39] March Hare: i wont allow you to speak about juliette like that

[12:39] Hugo Sabastien: or a dude or a mean old lady

[12:39] Juliette Dane: you tell them bitch

[12:40] Juliette Dane: March knows...am I mean and/or old, March?

\footnotetext{
${ }^{4}$ Juliette uses third person to refer to her own avatar, creating linguistic distance between them.
} 
[12:40] March Hare: no

[12:40] Hugo Sabastien: dude?

[12:40] Juliette Dane: suck on that, Hugo

[12:40] Juliette Dane: am I a dude, March?

[12:40] Hugo Sabastien: do u guys know each other in RL?

[12:40] March Hare: no

[12:41] Juliette Dane: nope

[12:41] Hugo Sabastien: so there is no proof

[12:41] Juliette Dane: lol

[12:41] Juliette Dane: Hugo I'll go on voice if you want you dumbass

[12:41] Hugo Sabastien: and im scoring for Ghana!

$[\ldots]$

[12:44] Juliette Dane: come on Hugo

[12:44] Juliette Dane: I'm on voice

$[\ldots]$

[12:46] Minister Alleluja: juliette is proving she's a girl

$[\ldots]$

[12:47] Minister Alleluja: hugo is proving he's annoying

[... Several minutes go by with technical difficulties in making the various voices audible. Once they are heard, Juliette is revealed to have a soprano female voice that is soft and quiet, with a British accent. The next chat speakers can hear the voices but are responding in typed chat instead of speaking themselves.]

[12:54] Hugo Sabastien: are u morphing ur voices?

[12:54] Irma Stone: hehe, first time i heard Juliette

$[\ldots]$

[12:55] River Rise: i can hear you hugo, yeah

[12:56] Irma Stone [responding to a voiced question from Juliette about why he laughed, "hehe"]: because I was surprised. I thought you would never.

[12:56] River Rise: god knows where my mic is though

[12:56] River Rise looks around the room

[12:56] River Rise [answering a voice comment]: yup juliette

[12:56] Irma Stone [responding to a question in voice about her surprise.]: Ah, donno. Just the first time. btw, nice voice.

$[\ldots]$

[12:59] Irma Stone: nice hearing your voice Juliette:)

Juliette is challenged to "prove she is a girl." And the standard Hugo demands is high: unless someone can corroborate her claim after having met her in real life "there is no proof" of her gender. The conventional wisdom in real life, as Hugo notes, is to "just believe my eyes" that the gender presented is the one that is accurate. In real life, pictures are often taken as final verification of identity - they are embossed into drivers' licenses, student identification cards, and passports. But Juliette has already complicated the matter of believing what is seen by including the photograph of the man in her real life profile. Moreover, she has displayed an 
apparently masculine knowledge of the World Cup sports tournament. These dissonant factors introduced by Juliette, taken together with the anxiety of the digital remove, means that anything less than seeing fails the standard of proof. Hugo asserts that for Juliette to claim that she is female is as outrageous as his claiming his identity to be African, a world class soccer player, and the hero of a World Cup game: "and im scoring for Ghana!" Juliette responds that if "just believing my eyes" is the measure at hand, then the gender of the avatar (clearly female) ought to be as convincing as the photograph ostensibly from real life: "yes, Juliette really looks like a dude," she says with sarcasm. This question is made more salient for this social group by facts and rumors about other residents in this philosophy simulation and elsewhere in virtual life who are verified by voice and other means to be male after years of purporting themselves to be female.

When Juliette offers to "go on voice" to prove her gender, Hugo's initial response is skepticism, asking if perhaps the voice is being "morphed," manipulated to change the vocal range and make a male voice sound female. Irma, however, seems quite convinced, saying with a smile: "nice hearing your voice juliette:)." And March, who stepped into a gallant's role ("i wont allow you to speak about Juliette like that") and is emasculated by Juliette as a reward ("you tell them bitch"), seems to be corroborated as accurate. Juliette's voice does confirm the broad category of female, but she sufficiently complicated her performance that she underscores the anxiety that attends to not-knowing in a digital context. The mostly-invisible technologies of culture that Juliette has used to establish a feminine identity are destabilized by the obvious technology of virtuality, introducing a new element of uncertainty into the everyday.

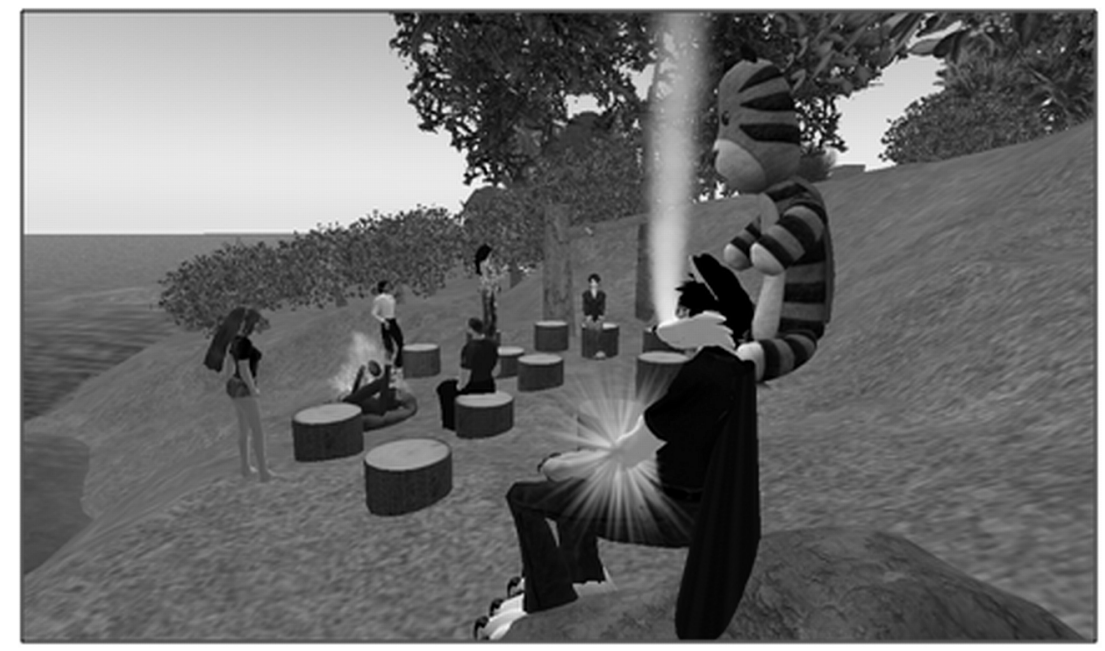

Discussion around a campfire 


\section{Conclusion}

Ethnography in virtual worlds allows us to look beyond generalizations to see how culture is actually lived, how identity and the character of existence can be constructed, performed as well as questioned. Gaia's creative greeting of apparent nonsense ("lalala lalala la la la lala") that comes a full two minutes before her more recognizable "whats going on," is both conservative and revisionary, both acknowledging norms through their delayed appearance and challenging them. Juliette, similarly, uses her performance of gender in ways that reaffirm and challenge normative evaluations of it. Both use the technology of computers to play with the technology of culture. Their performances unfold interactively, blurring distinctions between performer and audience as they creatively apply the conventions of engagement. The participants' jokes, framing of events, and allusions to other texts and contexts, as well as the norms they expect, the ones they adhere to, and the ones they deviate from are mutually constitutive. What we may discover, then, from divergences in what has become routine - including saying hello and assessing gender - is that the technology of the internet and the technology of culture not only express what we know but also shape what there is to know. The interactions discussed here reveal the social world we live in as existing between the poles of conservation and innovation, the individual enactment and the social context that gives it shape. Participants, with a foot in virtual and actual life, find these domains cannot be entirely disentangled because the elements that make up these performances emerge from and influence each other. Ethnographic examination of the performances of everyday life, and especially those places where performances diverge from the norm, let us uncover the rules and tools by which social life works. Through digital worlds, we can glimpse this convergence of technologies. In thus exposing technology's workings, we can tinker with them. In glimpsing how technology and culture shape our experience of the world, we can also imagine how to use them to construct the world we seek to live in.

\section{References}

Bauman, R. (1971): Verbal Art as Performance. Prospect Heights, IL: Waveland Press.

Bauman, R. (1983): The field study of folklore in context. In: R. M. Dorson, I. G. Carpenter, eds.: Handbook of American Folklore, pp. 362-368. Bloomington: Indiana University Press.

Bauman, R. (1986): Folklore, Cultural Performances, and Popular Entertainments: A Communications-Centered Handbook, pp. xiii-xxi. New York: Oxford University Press.

Ben-Amos, D. (1971): Toward a defnition of folklore in context. Journal of American Folklore, 84, pp. 3-15.

Blank, T. J. (2009): Folklore and the Internet: Vernacular Expression in a Digital World, pp. 1-20. Logan, UT: Utah State University Press. 
Boellstorff, T. (2008): Coming of Age in Second Life: An Anthropologist Explores the Virtually Human. Princeton, NJ: Princeton University Press.

Deleuze, G. (1968): Difference and Repetition. New York: Columbia University Press. Eagleton, T. (2000): The Idea of Culture. Malden, MA: Blackwell.

Hansen, M. (2010): Ubiquitous computing as environmental agency or towards a post phenomenology of micro-temporal sensations. Presentation, Indiana University, March 25, 2010.

Heidegger, M. (1962): Being and Time. Malden, MA: Blackwell.

Heidegger, M. (1977/93): The question concerning technology. In: D. F. Krell: Martin Heidegger: Basic Writings, pp. 307-342. New York: HarperCollins.

Howard, R. G. (2008): Electronic hybridity: the persistent processes of the vernacular web. Journal of American Folklore 121, pp. 192-218.

Kirschenblatt-Gimblett, B. (1995): From the paperwork empire to the paperless office: testing the limits of the 'Science of Tradition'. In: R. Bendix, R. L. Zumwalt, eds.: Folklore Interpreted: Essays in Honor of Alan Dundes, pp. 69-92. New York: Garland.

Lichty, P. (2011): People, affect, space. Presentation, Indiana University, April 6, 2011.

Moore, A.B. (Pink): Quotations. Good Reads, retrieved 8 February 2012, from http://www.goodreads.com/author/quotes/904429.

Robinson, J.M. (2012): Saying hello in a digital world: emergent performance and social competence. In: L. Monaghan, J. Goodman, J.M. Robinson, eds.: A Cultural Approach to Interpersonal Communication: Essential Readings, second edition, pp. 84-92.

Malden, MA: Wiley-Blackwell.

Wrathall, M. (2005): How to Read Heidegger. New York: Norton. 